\title{
Analysis of the genetic diversity of Candida isolates obtained from diabetic patients and kidney transplant recipients
}

\author{
Volmir Pitt Benedetti ${ }^{1,2} /{ }^{+}$, Daiani Cristina Savi ${ }^{2,3}$, Rodrigo Aluizio ${ }^{3}$, Douglas Adamoski ${ }^{3}$, \\ Vanessa Kava-Cordeiro3 ${ }^{3}$, Lygia V Galli-Terasawa ${ }^{3}$, Chirlei Glienke ${ }^{2,3}$
}

\begin{abstract}
${ }^{1}$ Universidade Paranaense, Departamento de Microbiologia, Francisco Beltrão, PR, Brasil ${ }^{2}$ Universidade Federal do Paraná, Departamento de Patologia Básica, Curitiba, PR, Brasil ${ }^{3}$ Universidade Federal do Paraná, Departamento de Genética, Curitiba, PR, Brasil

Yeasts of the genus Candida have high genetic variability and are the most common opportunistic pathogenic fungi in humans. In this study, we evaluated the genetic diversity among 120 isolates of Candida spp. obtained from diabetic patients, kidney transplant recipients and patients without any immune deficiencies from Paraná state, Brazil. The analysis was performed using the ITS1-5.8S-ITS2 region and a partial sequence of 28S rDNA. In the phylogenetic analysis, we observed a consistent separation of the species C. albicans, C. dubliniensis, C. glabrata, C. tropicalis, C. parapsilosis, C. metapsilosis and C. orthopsilosis, however with low intraspecific variability. In the analysis of the C. albicans species, two clades were formed. Clade A included the largest number of isolates (91.2\%) and the majority of isolates from GenBank (71.4\%). The phylogenetic analysis showed low intraspecific genetic diversity, and the genetic polymorphisms between C. albicans isolates were similar to genetic divergence found in other studies performed with isolates from Brazil. This low genetic diversity of isolates can be explained by the geographic proximity of the patients evaluated. It was observed that yeast colonisation was highest in renal transplant recipients and diabetic patients and that $\mathrm{C}$. albicans was the species most frequently isolated.
\end{abstract}

Key words: ITS1-5.8S-ITS2 and 28S rDNA - Candida - diabetes - renal transplant recipient

Infections caused by opportunistic fungi, such as Candida yeast, often affect patients undergoing organ or bone marrow transplants, AIDS patients, patients taking immunosuppressive drugs, patients undergoing cancer treatment, those having undergone major surgery, those of advanced age or premature infants (Wisplinghoff et al. 2004). It can also affect individuals suffering from chronic stress, patients with metabolic diseases such as diabetes, those who are malnourished and those taking broad-spectrum antibiotics (Roden et al. 2005).

The majority of fungal infections in humans are caused by the species $C$. albicans and $C$. glabrata. The prevalence rates of $C$. albicans and $C$. glabrata infections are approximately $70 \%$ and $15 \%$, respectively (Kolaczkowski et al. 2010). Infections caused by non-albicans Candida (NAC) species, such as $C$. tropicalis, $C$. parapsilosis, C. krusei, C. lusitaniae, C. inconspicua, $C$. lipolytica and $C$. norvegensis, have become increasingly more frequent; in some cases, infections with NAC species are predominant (Pfaller \& Diekema 2007, Kothavade et al. 2010). There is great genetic diversity among different yeast species, in particular C. albicans, and this characteristic may be explained by the presence of a diploid genome, predominantly clonal reproduction and a high rate of recombination (Jacobsen et al. 2008).

doi: 10.1590/0074-02760160042

+ Corresponding author: volmir@unipar.br

Received 8 February 2016

Accepted 16 May 2016
In the present study, we evaluated the genetic diversity among $C$. albicans isolates from diabetic patients and kidney transplant recipients and compared them to other isolates described in the literature. We also determined which species of Candida were involved in the colonisation of the oral cavity in diabetic patients and renal transplant recipients from southern Paraná state (Brazil), including with what frequency colonisation occurred. We also evaluated the intraspecific diversity of C. albicans and its population structure.

\section{MATERIALS AND METHODS}

Patients analysed - In total, 190 individuals were analysed, of which 64 were diabetic patients, 37 were kidney transplant recipients, and 89 had no immune deficiencies (control group). The diabetic patients were over 40 years old, had been diagnosed with type II diabetes for over five years, were not using insulin and had hypertension; 48 had hyperglycaemia. All transplant patients were over 30 years old and had a kidney transplant over one year ago; 19 patients were on the immunosuppressant prednisone. The control group was composed of people who were between the ages of 18 and 30, were not being treated for any disease and were not using drugs with antimicrobial or anti-inflammatory activities. An epidemiological survey of the patients was also performed to obtain more information.

Sample processing - Approximately $1 \mathrm{~mL}$ of saliva was collected from each patient according to the no stimulation method described by Navazesh \& Kumar (2008). After collection, $100 \mathrm{~mL}$ of saliva was inoculated in CHROagar ${ }^{\circledR}$ medium (Becton-Dickinson, Franklin Lakes, New Jersey, USA) and incubated at $25^{\circ} \mathrm{C}$ for five 
days. After incubation, the colony-forming units per $\mathrm{mL}$ saliva $(\mathrm{CFU} / \mathrm{mL})$ were determined. An initial screening of Candida was performed to assess biochemical assimilation (auxonograma), sugar fermentation (zymogram) and production of germ tubes (Kurtzman \& Fell 1998). Isolates were maintained by inoculating in Brain Heart Infusion medium (Difco) containing 20\% glycerol in Eppendorf tubes and storing at $-20^{\circ} \mathrm{C}$ (Silva et al. 2008).

Isolates and reference strains - The present study examined 120 yeast species isolated from 96 patients out of a 190-patient pool. The following reference Candida strains from the American Type Culture Collection (ATCC) were also used: C. albicans ATCC 44858, C. glabrata ATCC 2001 and C. tropicalis ATCC 28707. This research was approved by the Ethics Committee under registration number CAAE-0200.1.375.000-11 Paranaense University, Paraná (PR), Brazil).

DNA extraction - Genomic DNA was extracted using an Ultraclean Microbial DNA Isolation Kit $\left(\mathrm{MoBio}^{\circledR}\right)$ according to the manufacturer's instructions and stored at $-20^{\circ} \mathrm{C}$ after extraction.

Amplification of the ITS1, 5.8S, ITS2 and 28S rDNA regions - The primers V9G (de Hoog \& van den Ende 1998) and ITS4 (White \& Morrow 1990) were used to amplify the Internal Transcribed Spacer (ITS) regions and 5.8S rDNA. The primers LR0R and LR5 were used to amplify fragments of 28S rDNA (Vilgalys \& Hester 1990). Polymerase chain reaction (PCR) reactions were performed in a total volume of $25 \mu \mathrm{L}$, which contained Tris Base buffer solution ( $\mathrm{pH}$ 8.4) $(20 \mathrm{mM}), \mathrm{KCl}(50$ $\mathrm{mM})$, deoxynucleotide triphosphates (dNTPs) $(0.3 \mathrm{mM})$ (Invitrogen-Life Technologies, Brazil), $\mathrm{MgCl}_{2}(1.6 \mathrm{mM}$ ), primers $(15$ pmol each), Taq DNA polymerase $(0.5 \mathrm{U})$ (Invitrogen-Life Technologies, Brazil) and template DNA (20 ng). The amplification of the ITS regions and the $5.8 \mathrm{~S}$ gene was performed using the following protocol: $95^{\circ} \mathrm{C}$ for $5 \mathrm{~min} ; 30$ cycles of $95^{\circ} \mathrm{C}$ for $1 \mathrm{~min}, 57^{\circ} \mathrm{C}$ for $1 \mathrm{~min}$, and $72^{\circ} \mathrm{C}$ for $1 \mathrm{~min}$; and a final step at $72^{\circ} \mathrm{C}$ for 5 min. The amplification of the $28 \mathrm{~S}$ region was performed according to the following protocol: $95^{\circ} \mathrm{C}$ for $5 \mathrm{~min} ; 30$ cycles at $95^{\circ} \mathrm{C}$ for $1 \mathrm{~min}, 48^{\circ} \mathrm{C}$ for $1 \mathrm{~min}$, and $72^{\circ} \mathrm{C}$ for 1 $\mathrm{min}$; and a final step at $72^{\circ} \mathrm{C}$ for $5 \mathrm{~min}$.

PCR product purification - The PCR products $(25 \mu \mathrm{L})$ were purified using $7.5 \mathrm{M}$ ammonium acetate $(15 \mu \mathrm{L})$ and absolute ethanol $(74 \mu \mathrm{L})$. Samples were incubated on ice for $1 \mathrm{~h}$, followed by centrifugation for $45 \mathrm{~min}$ at $23,100 \mathrm{~g}$. The pellet was suspended in $12 \mu \mathrm{L}$ of MilliQ water.

$r D N A$ sequencing - Sequencing of the PCR products was performed using an ET Kit (DYEnamic ET Dye Terminator Cycle Sequencing for MegaBACE - Amersham Biosciences ${ }^{\circledR}$ ) according to the manufacturer's instructions. The products of the sequencing reaction were purified using Sephadex ${ }^{\mathrm{TM}}$ G-50 Fine DNA Grade resin and subjected to analysis by electrophoresis in a MegaBACE (Amersham Biosciences $^{\circledR}$ ) automated DNA sequencer.

Phylogenetic analysis - BioEdit 7.1.9 (Hall 1999) and MEGA 5.1 (Kumar et al. 2008) software were used for sequence editing and alignment. GARLI (Zwickl 2006) software was used for the maximum likelihood phylogenetic analysis, and MrBayes v.3.2.1 (Ronquist \& Huelsenbeck 2003) software was used for Bayesian inference analysis. A bootstrap procedure with 2,000 replicates was used to check node consistency. In the analyses of maximum likelihood and Bayesian inference, ModelTest software version 3.7 (Posada \& Crandall 1998) was used to create the evolutionary model. A phylogenetic tree was generated using sequences from 80 isolates, the ATCC - 44858 (KM361826) reference lineage, lineages from Paraná state [UFPR - HC04IC (KJ651886)] and from São Paulo state (USP - ICB945 (JX463265), UFC - CA1150 (AB861482), UNICAMP - CA70 (DQ141236), UNESP - CA15 (KF385990) and the UNIFESP isolates LEMI7986E (KC905077) and L8278 (KC408953). The sequence from the type strain CBS - 562 (NR125332) of $C$. albicans was also included in the analysis. All of the sequences analysed in this study were deposited in GenBank (KM361747- KM361866 and KM464557KM464676) (http://www.ncbi.nlm.nih.gov/genbank/).

\section{RESULTS}

Epidemiological aspects of isolated yeast - Of the 190 patient samples, $96(50.53 \%)$ contained yeast growth. A total of 120 strains belonging to the genus Candida were isolated from these 96 patient samples. Among the 37 samples from transplant recipients, yeast growth was observed in 19 (51.35\%); the average CFU/mL of the saliva was 814 . Among the 64 samples analysed from patients with diabetes, $44(68.75 \%)$ contained yeast growth; the average $\mathrm{CFU} / \mathrm{mL}$ was 932 . In the control group (89 patients), growth was observed in $33(37.08 \%)$ samples; the average CFU/mL of the saliva was 215 (Table). Of the 120 isolates, 80 strains were identified as $C$. albicans, 17 as C. parapsilosis, eight as C. tropicalis, six as C. glabrata, four as $C$. dubliniensis, three as C. metapsilosis and two as $C$. orthopsilosis (Table). The highest average CFU/ $\mathrm{mL}$ was observed in patients with diabetes and kidney transplants relative to the control group $(\mathrm{p}=0.01)$. Average CFU/mL values were 879 for C. parapsilosis, 854 for C. tropicalis, 649 for C. albicans, 520 for C. glabrata, 55 for C. dubliniensis, 47 for C. metapsilosis and 25 for C. orthopsilosis. The analysis of patient interview data revealed that gender did not affect yeast growth, as the growth index was $24(53.3 \%)$ among men and $72(49.7 \%)$ among women $(\mathrm{p}=0.90)$. There was also no correlation found among the different age groups $(<50$ years, 5160 years and $>60$ years) in terms of yeast isolation $(p=$ 0.09 ). Past candidiasis did not influence colonisation because yeast was isolated from $44(45.8 \%)$ patients with a previous history of oral candidiasis and from 52 (54.2\%) of patients with no history of oral candidiasis $(\mathrm{p}=0.13)$.

Phylogenetic analysis - To determine the intraspecific variability among $C$. albicans isolates, our isolates were compared to sequences of $C$. albicans isolated from Brazil that were deposited in GenBank. In the ITS1-5.8SITS2 phylogenetic tree of C. albicans isolates (Fig. 1), we observed the possible formation of two population groups. Clade A consists of the largest number of isolates, including ATCC-44858, the type strain C. albicans - CBS562 
TABLE

Epidemiological data of patients from whom yeast isolates were collected

\begin{tabular}{|c|c|c|c|}
\hline \multirow[b]{2}{*}{ Patients } & \multicolumn{3}{|c|}{ Epidemiological characteristics } \\
\hline & $\begin{array}{l}\text { Isolation frequency } \\
{ }^{a}(\mathrm{n})\end{array}$ & Average $\mathrm{CFU} / \mathrm{mL}^{\mathrm{b}}$ & $\begin{array}{l}\text { Species isolated } \\
\text { c(n) }\end{array}$ \\
\hline Kidney transplant & $51.35 \%(19)$ & 814 & $\begin{array}{c}\text { Candida albicans }(15) \\
\text { C. parapsilosis }(1) \\
\text { C. glabrata }(2) \\
\text { C. tropicalis (2) } \\
\text { C. metapsilosis }(1) \\
\text { C. orthopsilosis }(1)\end{array}$ \\
\hline Diabetic & $68.75 \%(44)$ & 932 & $\begin{array}{l}\text { C. albicans }(39) \\
\text { C. parapsilosis }(10) \\
\text { C. glabrata }(1) \\
\text { C. tropicalis }(5) \\
\text { C. dubliniensis }(1) \\
\text { C. metapsilosis }(2) \\
\text { C. orthopsilosis }(1)\end{array}$ \\
\hline Control group & $37.08 \%(33)$ & 215 & $\begin{array}{l}\text { C. albicans }(26) \\
\text { C. parapsilosis }(6) \\
\text { C. glabrata }(3) \\
\text { C. tropicalis }(1) \\
\text { C. dubliniensis }(3)\end{array}$ \\
\hline
\end{tabular}

a: number of patients whose saliva samples contained yeast.

b: CFU/mL - colony-forming units per $1 \mathrm{~mL}$ of saliva.

c: number of Candida species isolated per patient type.

and isolates from different Brazilian states including Paraná state (HC04IC/UFPR, KJ651886/GB), São Paulo state (ICB945/USP, JX463265/GB; CA70/UNICAMP, DQ141236/GB; and CA15/UNESP, KF385990/GB) and Ceará state (CA1150/UFC, AB861482/GB) (Neto et al. 2014). Isolates belonging to Clade A had no genetic divergence in the ITS1-5.8S-ITS2 rDNA region. The isolates with the highest genetic diversity were in Clade B (CA29PD, CA32PD, CA38PD, CA59PT, CA61PT, CA62PT, CA63PT and CA84PD) (Fig. 1).

In the phylogenetic tree, assembled with 120 isolates belonging to seven different Candida species in which sequences from the ITS1 and ITS2 regions and the 5.8S and $28 \mathrm{~S}$ rDNA genes were used, there is a consistent separation of the following species: C. albicans, $C . d u b-$ liniensis, C. glabrata, C. tropicalis and the three species that formed the C. parapsilosis complex (C. parapsilosis, C. metapsilosis and C. orthopsilosis). Moreover, we were able to observe low intraspecific variability (Fig. 2).

\section{DISCUSSION}

Analyses of different epidemiological aspects of the Candida species may assist in disease prevention, control and treatment. In our analysis, yeast colonisation was more frequently observed in renal transplant recipients and diabetic patients (Table) than in the control group. This finding indicates that patients with altered immune responses are more susceptible to fungal infection, which is in agreement with Kothavade et al. (2010). The high Candida colonisation observed in diabetic patients is correlated with multifactorial events that are influenced by factors such as high concentrations of sugars (sucrose, glucose and fructose) in tissues and low levels of salivary secretions (Khovidhunkit et al. 2009). A high frequency of colonisation in diabetic patients has been previously observed (Menezes et al. 2007, Sashikumar \& Kannan 2010, Obradović et al. 2011). In addition, Colombo et al. (2012) reported that diabetes mellitus is one of the most common pathological disorders predisposing adult patients to the development of different clinical forms of candidiasis.

Our results show that $C$. albicans was the most frequently isolated species among all patient groups (Table). C. albicans is a yeast species of wide genetic variability and great adaptability to different anatomical sites, likely explaining its high frequency of isolation from human hosts (Zhou \& Lorenz 2008, Yan et al. 2009). A clear example of this correlation between colonisation and pathogenicity is the fact that $C$. albicans is responsible for $90 \%$ of oral and oesophageal candidiasis episodes (Colombo et al. 2012).

Although C. albicans is still the most common pathogen involved in candidiasis, a significant increase in NAC infections has been observed recently (Arancia et al. 2009); in particular, C. glabrata, C. krusei, C. tropicalis and $C$. parapsilosis have been found to be etiological agents of disease (Silva 2014). In our study, one-third of 


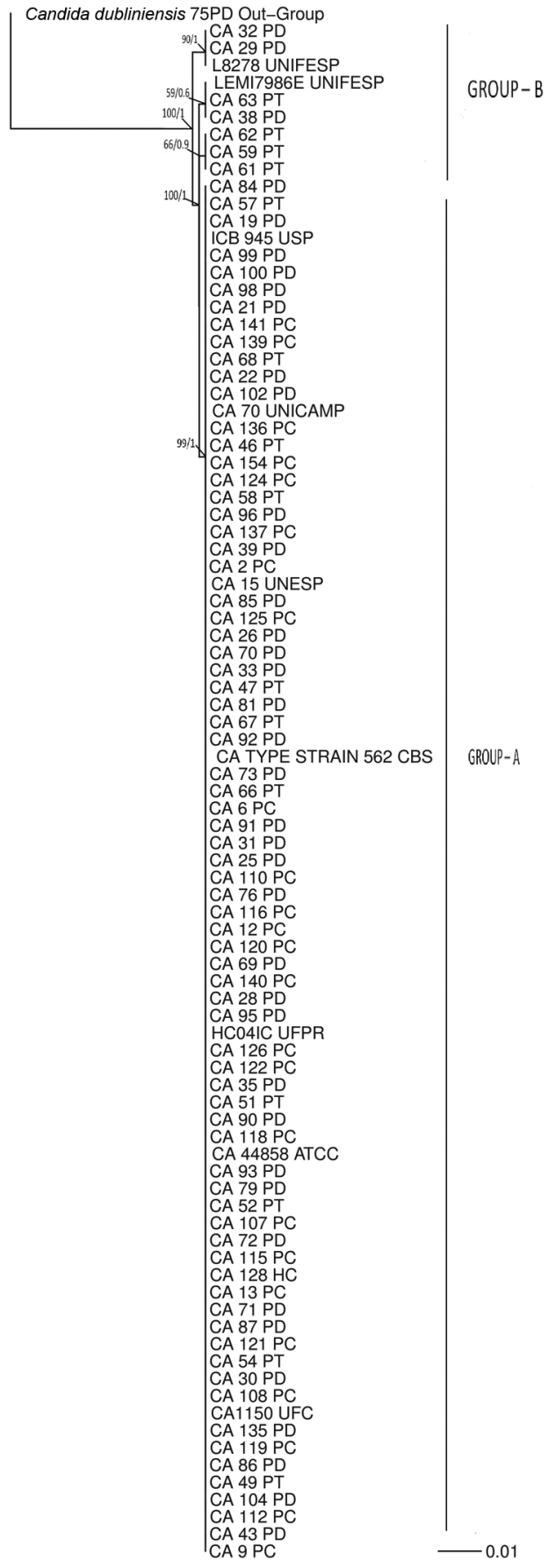

Fig. 1: Bayesian inference phylogenetic tree of Candida albicans isolates and reference strains generated using ITS1-5.8S-ITS2 of rDNA sequences. Bootstrap values of maximum likelihood and Bayesian posterior probability values are shown above nodes. The $C$. dubliniensis isolate was used as the outgroup. The scale bar indicates the number of expected changes per site.

the isolates identified were NAC species (Table). According to Hsueh et al. (2005), increases in colonisation with NAC species are associated with extensive prophylactic use of antifungal drugs in immunocompromised patients.
It was also observed that $C$. parapsilosis was frequently isolated as an accompanying species in the present study. This result corroborates the guidelines for the management of candidiasis as described by Colombo et al. (2012). Here, the authors classified C. parapsilosis as one of the most common agents of candidaemia in Latin America, in particular Brazil. This type of infection mainly affects hospitalised patients using central venous catheters.

In our study, certain epidemiological aspects, such as gender, age and candidiasis history, did not influence the colonisation of Candida species in the oral cavity of the analysed patients. These results confirm those of Obradović et al. (2011), who determined that oral cavity colonisation was not associated with gender. Our results are also in agreement with studies by Belazi et al. (2005), who did not observe an association between oral candidiasis and patient gender or age. Hof (2010) suggests that increases in the frequency of oral candidiasis may be associated with poor oral hygiene, specific diets, use of dental prosthesis or other diseases of the oral mucosa.

The genetic diversity among $C$. albicans isolates was analysed (Fig. 1), and the formation of two population groups was observed. Group A consisted of the largest number of isolates in this study, as well the type strain and strains from other Brazilian states. Group B included seven isolates and the strains LEMI7986E (KC905077/GB) and L8278 (KC408953/GB) belonging to UNIFESP University (São Paulo state) (Merseguel et al. 2015). Despite the formation of two groups, low genetic diversity was observed between the isolates collected from Paraná state (Federal University of Paraná) when compared to strains from different Brazilian states. It was also observed that specific phylogenetic groups were not formed based on the type of patient (renal transplant recipient, diabetic or control group). The two groups formed were $98.8 \%$ similar with five polymorphic sites in the $412 \mathrm{bp}$ analysed (four sites in the ITS region and one site in the $5.8 \mathrm{~S}$ region). However, this last substitution is a mutation. Therefore, we suggest that regions other than ITS and 5.8S should be analysed for intraspecific studies of this group.

Some studies have suggested that species of $C$. albicans, although isolated from different patients, can have low variability despite having very similar genomes (Odds et al. 2006). Candida spp, which is present in many different anatomical sites in the human body, may have passed from one individual to another as populations migrated; this would explain the low genomic variability observed (Odds et al. 2008). Additionally, some studies suggest that most individuals are colonised or infected by one single strain of Candida; more significant genetic differences may exist between isolates of different geographic origins (Soll \& Pujol 2003). Large diversity in a population of $C$. albicans may be the result of different sources, as observed in the work of Shin et al. (2011) and Hammarskjöld et al. (2013). The low variability found among the $C$. albicans isolates in the present study could be explained by the geographic proximity of the patients, as was determined in studies by Martens et al. (2007) and Aserse et al. (2012).

A phylogenetic tree was formed using the sequences of seven different Candida species (Fig. 2) and showed 


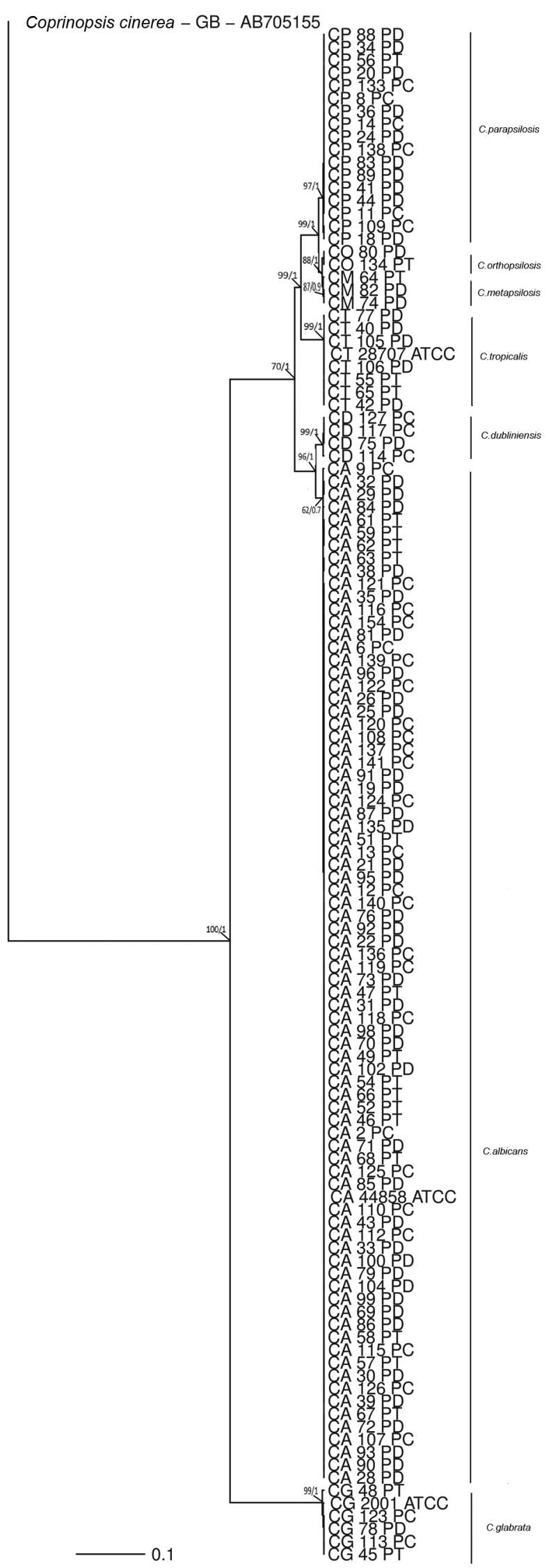

Fig. 2: Bayesian inference phylogenetic tree of seven Candida species. The tree was built using concatenated sequences of the ITS and $28 \mathrm{~S}$ genes. Bootstrap values of maximum likelihood and Bayesian posterior probability values are shown above nodes. The Coprinopsis cinerea isolate was used as the outgroup. The scale bar indicates the number of expected changes per site.

the formation of distinct branches for each species. However, with low intraspecific variability and despite the genetic proximity of the C. parapsilosis complex (Roy \& Meyer 1998), the separation of the complex into distinct species was required, as was also reported by Tavanti et al. (2005) and Carvalho et al. (2013).

In conclusion, yeast colonisation of the oral cavity occurs more frequently in renal transplant recipients and diabetic patients than in healthy individuals. Sequences of ITS and rDNA regions were able to correctly identify Candida species and can be used for accurate species identification for this genus. C. albicans was the most frequently isolated species regardless of patient gender or age. The phylogenetic study showed that $C$. albicans isolates have low genetic diversity based on rDNA sequences, and the formation of two population groups was observed. However, these groups had no correlation with respect to gender, age or region of isolation.

\section{REFERENCES}

Arancia S, Sandini S, Cassone A, de Bernardis F. Use of $65 \mathrm{kDa}$ mannoprotein gene primers in PCR methods for the identification of five medically important Candida species. Mol Cell Probes. 2009; 23(5): 218-26.

Aserse AA, Räsänen LA, Assefa F, Hailemariam A, Lindström K. Phylogeny and genetic diversity of native rhizobia nodulating common bean (Phaseolus vulgaris L.) in Ethiopia. Syst Appl Microbiol. 2012; 35(2): 120-31.

Belazi M, Velegraki A, Fleva A, Gidarakou I, Papanaum L, Baka D, et al. Candidal overgrowth in diabetic patients: potential predisposing factors. Mycoses. 2005; 48(3): 192-6.

Carvalho VO, Okay TS, Melhemc MSC, Szeszs MW, del Negro GMB. The new mutation L321F in Candida albicans ERG11 gene may be associated with fluconazole resistance. Rev Iberoam Micol. 2013; 30(3): 209-12.

Colombo AL, Guimarães T, Camargo LF, Richtmann R, QueirozTelles FD, Salles MJ, et al. Brazilian guidelines for the management of candidiasis: a joint meeting report of three medical societies: Sociedade Brasileira de Infectologia, Sociedade Paulista de Infectologia, Sociedade Brasileira de Medicina Tropical. Braz J Infect Dis. 2012; 17(3): 283-312.

de Hoog GS, van den Ende AHG. Molecular diagnostics of clinical strains of filamentous basidiomycetes. Mycoses. 1998; 41(5-6): 183-9.

Hall TA. BioEdit: a user-friendly biological sequence alignment editor and analysis program for Windows 95/98/NT. Nucleic Acids Symp Ser. 1999; 41: 95-8.

Hammarskjöld F, Mernelius S, Andersson RE, Berg S, Hanberger H, Löfgren S, et al. Possible transmission of Candida albicans on an intensive care unit: genotype and temporal cluster analyses. J Hosp Infect. 2013; 85(1): 60-5.

Hof H. Mycoses in the elderly. Eur J Clin Microbiol Infect Dis. 2010; 29(1): 5-13. 
Hsueh PR, Lau YJ, Chuang YC, Wan JH, Huang WK, Shyr JM, et al. Antifungal susceptibilities of clinical isolates of Candida species, Cryptococcus neoformans, and Aspergillus species from Taiwan: surveillance of multicenter antimicrobial resistance in Taiwan program data from 2003. Antimicrob Agents Chemother. 2005; 49(2): 512-7.

Jacobsen MD, Davidson AD, Li SY, Shaw DJ, Gow NAR, Odds FC. Molecular phylogenetic analysis of Candida tropicalis isolates by multilocus sequence typing. Fungal Genet Biol. 2008; 45(6): 1040-2.

Khovidhunkit SO, Suwantuntula T, Thaweboon S, Mitrirattanakul S, Chomkhakhai U, Khovidhunkit W. Xerostomia, hyposalivation, and oral microbiota in type 2 diabetic patients: a preliminary study. J Med Assoc Thai. 2009; 92(9): 1220-8.

Kolaczkowski M, Kolaczkowska A, Sroda K, Ramalhete C, Michalak $\mathrm{K}$, Mulhovo S, et al. Substrates and modulators of the multidrug transporter CDR1p of Candida albicans in antifungal extracts of medicinal plants. Mycoses. 2010; 53(4): 305-10.

Kothavade RJ, Kura MM, Valand AG, Panthaki MH. Candida tropicalis: its prevalence, pathogenicity and increasing resistance to fluconazol. J Med Microbiol. 2010; 59(Pt 8): 873-80.

Kumar S, Nei M, Dudley J, Tamura K. MEGA: a biologist-centric software for evolutionary analysis of DNA and protein sequences. Brief Bioinform. 2008; 9(4): 299-306.

Kurtzman CP, Fell JW. The yeasts: a taxonomic study. New York: Elsevier Science; 1998.

Martens M, Delaere M, Coopman R, De Vos P, Gillis M, Willems A. Multilocus sequence analysis of Ensifer and related taxa. Int $\mathrm{J}$ Syst Evol Microbiol. 2007; 57(Pt 3): 489-503.

Menezes EA, Augusto KL, Freire CCF, Cunha FA, Montenegro RM, Montenegro RMJ. Frequência e atividade enzimática de Candida spp. na cavidade oral de pacientes diabéticos do serviço de endocrinologia de um hospital de Fortaleza-CE. J Bras Patol Med Lab. 2007; 43(4): 241-4.

Merseguel KB, Nishikaku AS, Rodrigues AM, Padovan AC, Ferreira RC, Melo ASA, et al. Genetic diversity of medically important and emerging Candida species causing invasive infection. BMC Infect Dis. 2015; 15: 57.

Navazesh M, Kumar SK. Measuring salivary flow challenges and opportunities. J Am Dent Assoc. 2008; 139: S35-S40.

Neto JBA, da Silva CR, Neta MAS, Campos RS, Siebra JT, Rose AC, et al. Antifungal activity of naphthoquinoidal compounds in vitro against fluconazole-resistant strains of different Candida species: a special emphasis on mechanisms of action on Candida tropicalis. PLoS ONE. 2014; 9(5): 1-10.

Obradović RR, Kesić LG, Pejčić NA, Petrović MS, Živković ND, Živković DM. Diabetes mellitus and oral candidiasis. Acta Stomatol Naissi. 2011; 27: 1025-34.

Odds FC, Davidson AD, Jacobsen MD, Tavanti A, Whyte JA, Kibbler $\mathrm{CC}$, et al. Candida albicans strain maintenance, replacement, and microvariation demonstrated by multilocus sequence typing. J Clin Microbiol. 2006; 44(10): 3647-58.

Odds FC, Jacobsen MD. Multilocus sequence typing of pathogenic Candida species. Eukaryot Cell. 2008; 7(7): 1075-84.
Pfaller MA, Diekema DJ. Epidemiology of invasive candidiasis: a persistent public health problem. Clin Microbiol Rev. 2007; 20(1): 133-63.

Posada D, Crandall KA. Modeltest: testing the model of DNA substitution. Bioinformatics. 1998; 14(9): 817-8.

Roden MM, Zaoutis TE, Buchanan WL, Knudsen TA, Sarkisova TA, Schaufele RL, et al. Epidemiology and outcome of zygomycosis: a review of 929 reported cases. Clin Infect Dis. 2005; 41(5): 634-53.

Ronquist F, Huelsenbeck JP. MRBAYES 3: bayesian phylogenetic inference under mixed models. Bioinformatics. 2003; 19(12): 1572-4.

Roy B, Meyer SA. Confirmation of the distinct genotype groups within the form species Candida parapsilosis. J Clin Microbiol. 1998; 36(1): 216-8

Sashikumar R, Kannan R. Salivary glucose levels and oral Candida carriage in type II diabetics. Oral Surg Oral Med Oral Pathol Oral Radiol Endod. 2010; 109(5): 706-11.

Shin JH, Bougnoux ME, d'Enfert C, Kim SH, Moon CJ, Joo MY, et al. Genetic diversity among Korean Candida albicans bloodstream isolates: assessment by multilocus sequence typing and restriction endonuclease analysis of genomic DNA by use of BssHII. J Clin Microbiol. 2011; 49(7): 2572-7.

Silva JO, Costa PP, Reche SHC. Manutenção de leveduras por congelamento a $-20^{\circ} \mathrm{C}$. Rev Bras Anal Clin. 2008; 40(1): 73-4.

Silva ZDL, João E, Maduro AP, Gandolfi L, Pratesi R, Martins MLM, et al. Candidíase vulvovaginal: distribuição e identificação molecular das espécies e perfil de resistência aos antifúngicos em Portugal e Cabo-Verde. In: $4^{\circ}$ Simpósio Internacional de Microbiologia Clínica; 2014 Out 22-24; João Pessoa, Brasil. João Pessoa: Sociedade Brasileira de Microbiologia; 2014. p. 216-22.

Soll DR, Pujol C. Candida albicans clades. FEMS Immunol Med Microbiol. 2003; 39: 1-7.

Tavanti A, Davidson AD, Gow NA, Maiden MC, Odds FC. Candida orthopsilosis and Candida metapsilosis spp. nov. to replace Candida parapsilosis groups II and III. J Clin Microbiol. 2005; 43(1): 284-92.

Vilgalys R, Hester M. Rapid genetic identification and mapping of enzymatically amplified ribosomal DNA from several Cryptococcus species. J Bacteriol. 1990; 172(8): 4238-46.

White JJF, Morrow AC. Endophyte-host associations in forage grasses. XII. A fungal endophyte ot Trichachne insularis belonging to Psedocercosporella. Mycologia. 1990; 82(2): 218-26.

Wisplinghoff H, Bischoff T, Tallent SM, Seifert H, Wenzel RP, Edmond MB. Nosocomial bloodstream infections in US hospitals: analysis of 24,179 cases from a prospective nationwide surveillance study. Clin Infect Dis. 2004; 39(3): 309-17.

Yan L, Li M, Cao Y, Gao P, Cao Y, Wang Y, et al. The alternative oxidase of Candida albicans causes reduced fluconazole susceptibility. J Antimicrob Chemother. 2009; 64(4): 764-73.

Zhou H, Lorenz MC. Carnitine acetyltransferases are required for growth on non-fermentable carbon sources but not for pathogenesis in Candida albicans. Microbiology. 2008; 154(Pt 2): 500-9.

Zwickl DJ. Genetic algorithm approaches for the phylogenetic analysis of large biological sequence datasets under the maximum likelihood criterion [PhD dissertation]. Austin: University of Texas at Austin; 2006. 